\title{
Inverse Force Estimation in a New Lab Simulation Approach for Vibration Prediction of Building-Mounted Small Wind Turbine
}

\author{
Bo Ren* \\ Structural Engineering, Faculty of Engineering, Sheffield University, Sheffield, \\ $U K$ \\ gongchengshi123@163.com
}

\begin{abstract}
The structural vibration generated by building mounted small wind turbine was fully investigated by author. In order to achieve this, the real vibration condition of wind turbine in field was accurately simulated in Lab for research. There are some difficulty during the whole simulation process for further quantification of vibration levels. One of the main concerns was the correct estimation of the excitation or contact force at the interface between vibration source (turbine) and receiver (building or walls). However, the relevant simulation method in Lab is not available so far. In this paper, the direct measurement of force was investigated and found unsuitable. A new simulation method was proposed including solving the problem of power supply (DC electric motor used), automatic control of rotational speed of motor and indirect interface force determination. At last, the new established finite element models (FEM) was validated by experimental data with a good initial agreement.
\end{abstract}

Keywords: New Lab simulation method, vibration prediction, FEMs, validation, building mounted small wind turbines, contact/excitation force, rotational speed control

\section{Introduction}

A large number of building mounted small wind turbines (BMSWT) have been used and developed recently in both wind energy industry and renewable technology which have been regarded as a novel technique of wind power usage in UK. The reason for this is the utilization of BMSWT can be more effective, applicable, flexible and cost lower when compared with the traditional large wind mill or farm. However, before mounting this particular small turbine, it is necessary to predict the vibration levels of it during its working status. The prediction results will help the engineer to make a final decision whether this particular site is suitable for mounting this type of wind turbine.

In the past few years, finite element models (FEMs) have been demonstrated as a useful tool to predict vibration levels in the scope of structural dynamics. Above all, [1] described the functions of the finite element (FE) computer programs for vibration quantification, among them, ANSYS was recommended and used in this paper. In ANSYS, the user need to define the finite element type which constitute the structure. In order to simulate building mounting status of wind turbine in field, a free stand wall in Lab (Figure 1) was adopted for mounting during the simulation process. If this is the case, shell element was recommended by [2] for this wall type in 3-D modelling which is usually considered as a plate structure since the ratio of thickness and width is less than 0.1. Moreover, [22-25] represented the most recent progress of development of methodology regarding vibration prediction in the past three years. All the above research provides an inspiration of the new approach developed here. 



\section{Figure1. Physical Observation and Schematic View (Geometry) of Free} Stand Wall

In finite element analysis (FEA), every finite element will be assigned a set of material parameter to present the material property. The most important parameters among them are E (Young's modulus), $v$ (Poisson's ratio) and $\rho$ (density). Here the literature review is necessary for parameter estimation. The free stand wall is a masonry brickwork, [3-6] did some primary research regarding the masonry walls and found that Poisson's ratio has a minimal effect on structural dynamic response compared to other parameters and hence recommended to have a constant value of 0.25 .

[5] did a comparison of Young's modulus of both brick and mortar for two types of masonry. In $1^{\text {st }}$ type, $E_{b}=10.0 \mathrm{GPa}, E_{m}=9.0 \mathrm{GPa}$; In $2^{\text {nd }}$ type, $E_{b}=6.5 \mathrm{GPa}, E_{m}=$ $6.3 \mathrm{GPa}$. Table 1 showed the numerical scale of Young's modulus and density derived from [6]'s work. The upper and lower limit were determined by both [6]'s tests and the extensive reference manual [11].

Table 1. Numerical Scale of Young's Modulus and Density of Masonry from [6]'s Research

\begin{tabular}{|c|c|c|c|c|}
\hline \multirow{2}{*}{ Component } & Material type & \multicolumn{2}{|c|}{ Modulus of elasticity } & Density \\
\hline \multirow{2}{*}{ Walls } & \multirow{2}{*}{ Brick } & Low $(\mathrm{GPa})$ & High $(\mathrm{GPa})$ & Nominal (kg/m3) \\
\cline { 3 - 5 } & & 7.5 & 11 & 2100 \\
\hline
\end{tabular}

After reviewing the above standards and literatures, the final estimation values which would be used in this paper were determined by the measurement of a series of static testing in Lab:

Table 2. Material Properties of Initial FE Model

\begin{tabular}{|c|c|}
\hline Material Parameters & Adopted Values \\
\hline Young's modulus (N/m2) & $10.5 \mathrm{e} 9$ \\
\hline Density $(\mathrm{kg} / \mathrm{m} 3)$ & 2130 \\
\hline Poisson's ratio & 0.25 \\
\hline
\end{tabular}

Once the material parameters had been determined, the initial FEM was built up based on ANSYS with certain boundary conditions which will be discussed here. The bottom end of the wall was treated as fix edge since the free stand wall is resting on the concrete floor without moving. A more complex situation was found at the left end (Figure 2) 
which need attention. Although the connection at left end is complicated, it is still made of mortar or clay as shown in Figure 2 which was considered as a clay strip according to the geometry of it. This is similar to the pinned boundary condition discussed in [2] for plate and shell. In [2]'s theory, if the edge is pinned supported, the deflection of it should be zero: $(w)_{x=a}=0$. Meanwhile, it can rotate without restrictions and bending moments $M_{x}$ along it should also be zero: $\left(\frac{\partial^{2} w}{\partial x^{2}}+v \frac{\partial^{2} w}{\partial y^{2}}\right)_{x=a}=0$. If performed in ANSYS, this boundary condition should be defined as: $(w)_{x=a}=0 ; \frac{\partial w}{\partial x} \neq 0 ; \frac{\partial w}{\partial y}=0$.

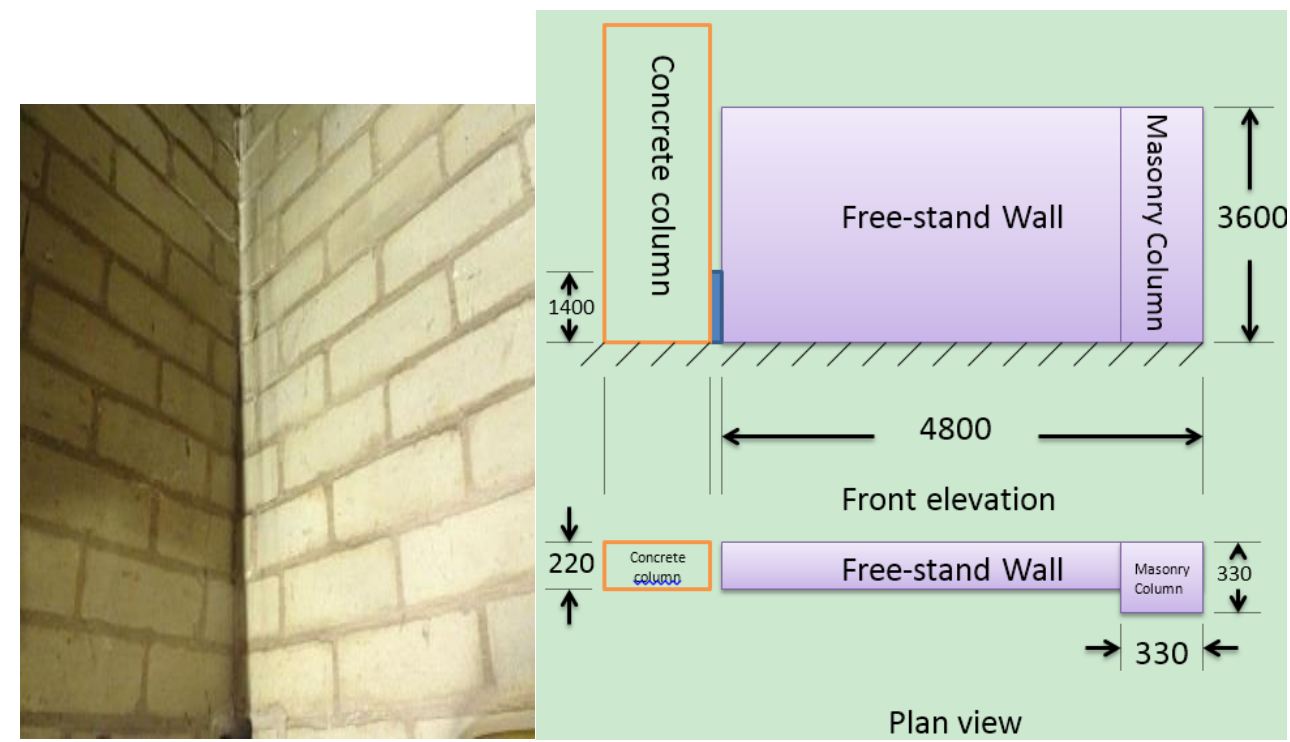

Figure 2. Overview of Pinned Connection (Left: Physical Observation of Left End; Right: Schematic View and Geometry of Left Interface)

\section{Theoretical Modal Analysis}

Theoretical Modal Analysis is one of the vibration or structural dynamics analysis in FEA, the purpose of it is to obtain the most important modal parameters of vibration, this is achieved through performing a theoretical analysis of free vibration without excitation force in the scope of structural dynamics using ANSYS. Above all, the physical model of free stand wall would be converted to a simplified geometrical model representing a thin plate structure in ANSYS (assuming $x$ and $y$ axes parallel to the plate plane). Here only pure bending were taken into account without considering the effect of torsion and shear according to the classic thin plate bending theory [2]. This effect will be reflected on the adoption of degree of freedoms (DOFs): only 3 DOFs considered in this analysis, i.e. translational movement in $\mathrm{z}$ axis (UZ), rotational movement in $\mathrm{x}$ (ROTX) and $\mathrm{y}$ axis (ROTY). The important modal parameters would be obtained after this analysis (e.g. natural or modal frequency, mode shape etc.) which tabulated in the following tables:

Table 3. Initial Prediction of Natural Frequencies

\begin{tabular}{|c|c|c|c|c|c|}
\hline Mode No. & 1 & 2 & 3 & 4 & 5 \\
\hline Predicted f. (Hz) & 6.4953 & 14.395 & 37.820 & 41.869 & 53.054 \\
\hline
\end{tabular}


Table 4. Theoretical Mode Shapes



These parameters would be used to predict or quantify vibration levels in harmonic analysis which is one of the structural analysis for rotational machinery. However, before post-processing, they need to be validated by experimental results to become robust and rigorous.

\section{Experimental Modal Analysis (Impact Testing)}

If we want to conduct a validation or updating process, the experimental modal parameter should be obtained by impact testing which is one of the structural testing for vibration analysis.

Above all, both the impact force of excitation generated from the impact hammer and the corresponding response (acceleration) of vibration generated from the wall will be captured by the relevant transducers on the accelerometers and hammer. Piezoelectric transducers rely on the piezoelectric effect of quartz or ceramic crystals to generate an electric output that is proportional to applied signal (e.g. acceleration, force etc.). However, the charge produced by a transducer is very small, the electrical signal produced by the transducer is susceptible to noise, and sensitive electronics must be used to amplify and condition the signal. Electrodes collect and wires transmit the charge to a signal conditioner that may be remote or built into the transducer. Sensors containing built-in signal conditioners are classified as integrated Electronics Piezoelectric (IEPE). IEPE makes the logical step of integrating the sensitive electronics as close as possible to the transducer to ensure better noise immunity and more convenient packaging.

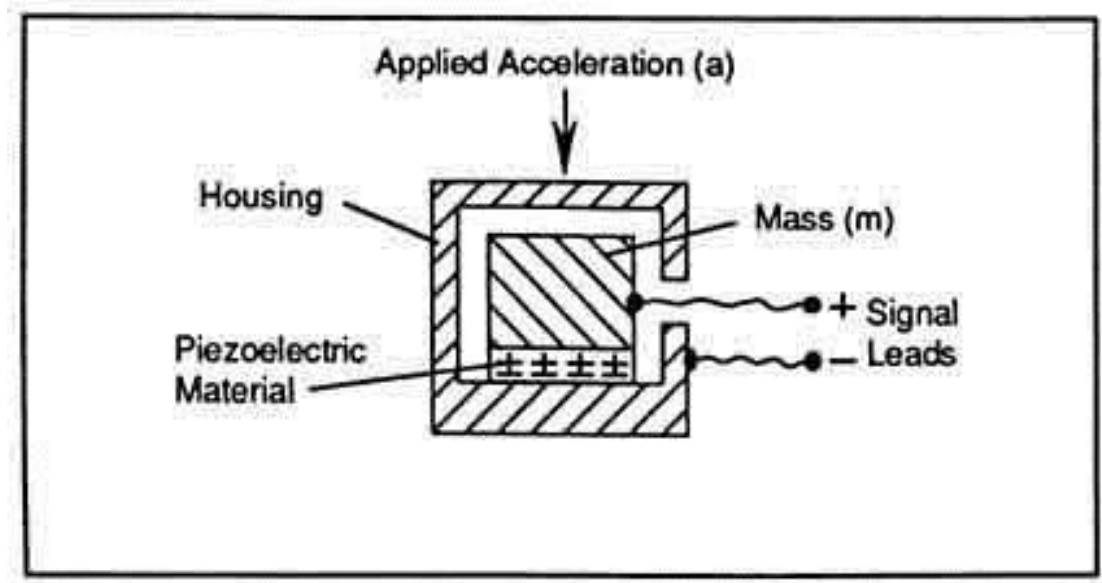

\section{Figure 3. Schematic Diagram of Piezoelectric Principle}

The force signal will be captured by an IEPE impact hammer (DEVECO impulse hammer Model 086D20, sensitivity: 1mv/lbf)-large sledge, tests very heavy structures such as buildings, ships and foundations at low to very low frequencies. IEPE's Modally 
Tuned impact hammers are easy-to-use solutions for delivering impulse forces into test specimens and providing electrical measurement signals of the amplitude and frequency content of the applied force. A selection of tips are included with each hammer which, along with an extender mass, allow the hammer to be tailored to deliver the desired frequency content of the impulse force waveform the structure under test.

Response accelerometers (PCB 336c, sensitivity: $1000 \mathrm{mv} / \mathrm{g}$ ) then measure the resultant motion of the test specimen for such requirements as resonance detection, modal analysis, transfer characteristics and structural determination.

Once the charge is conditioned by the signal conditioning electronics, the signal is available for display, recording, analysis, or control by a 16 channel data acquisition (DAQ) connecterswhich is called LMS Pimento FFT Analyzer. This analyzer did the program control via the LMS software, the signal will be transferred to SP92 (A/D \& digital signal processing module) via different signal-conditioning module. SP92 adopted the world-leading $\Sigma-\Delta$ technique with very low background noise and 24 bit fully linear A/D (up to $204.8 \mathrm{kHz}$ sample rate). The integration of high-speed simultaneous data transmission and one 24-bit high quality DSP of each 4 or 12 channels ensures the capabilities of simultaneous data transmission of multiple channels. The data processing functions include calibration, digital filtering wave, sampling, mode number tracing, extraction of harmonic wave and 1/3 or 1/12 octave band filtering wave. This equipment also did the required fast Fourier Transform (FFT) and other necessary mathematical transforms for signal processing in frequency domain.

LMS vibration \& structural professional software TEST XPRESS 7A will analyze the impact test to find frequency response functions using multitude of parallel online processing functions (Time, Spectrum, FRF, ...) It will support for both fixed location as roving hammer measurements and setting hammer-related acquisition parameters (Table 5) for comprehensive view on measured/missing data integrated with a geometrical view of the structure. The corresponding modal parameters were calculated by LMS Lab Test 12B via an advanced modal analysis technique PolyMAX and verified via modal synthesis and validation techniques.

Table 5. Data Acquisition Parameters for Normal Test FRF Measurements

\begin{tabular}{|c|c|c|c|}
\hline \multicolumn{2}{|c|}{ Acquisition Settings } & Cutoff & $20 \%$ \\
\hline Bandwidth & $3200 \mathrm{~Hz}$ & Response & Exponential \\
\hline Acquisition time & $0.32 \mathrm{~s}$ & Decay & $100 \%$ \\
\hline Resolution & $3.13 \mathrm{~Hz}$ & \multicolumn{2}{|c|}{ FRF Settings } \\
\hline \multicolumn{2}{|c|}{ Windowing } & FRF estimators & $\mathrm{H} 1$ \\
\hline Input & Force-Exponential & Averages & 5 \\
\hline
\end{tabular}

The coherence function will be calculated to validate the obtained measurement data.That is, by using the multi-channel spectrum analyzer both,the cause and the effect signals were collected and compared and only when their ratio was found to be near 1.0, were accepted. The whole Lab test rig was set up in Figure 4. 


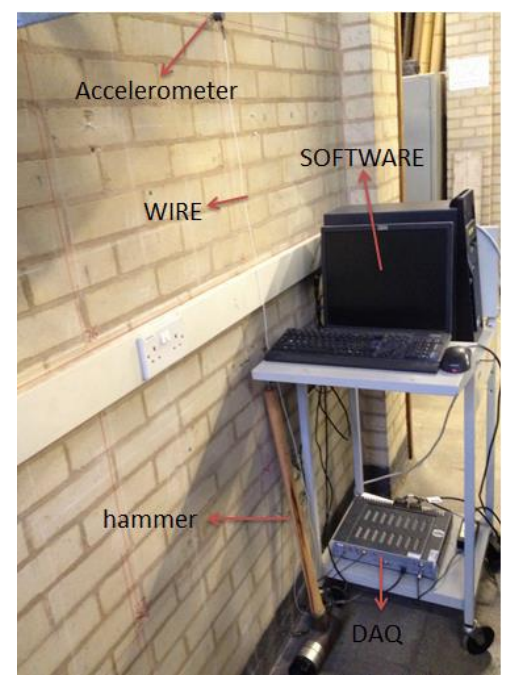

Figure 4. Test Rig of Impact Test with Measurement System

As required by impact test, different points on the wall need to be excited by hammer and their response should be measured by the transducers. In order to achieve this, the wall surface would be grid into different reference points (RPs) which is similar to the concept of finite element of structure which is widely used in automotive engineering. Once the whole structural testing finished, the experimental modal parameters (e.g. experimental modal frequency, experimental mode shape etc.) would be obtained by the post-processing of the software mentioned above:

\section{Table 5. Experimental Natural Frequencies Derived from Measurement}

\begin{tabular}{|c|c|c|c|c|c|}
\hline Mode No. & 1 & 2 & 3 & 4 & 5 \\
\hline Measured f. (Hz) & 3.678 & 9.589 & 21.067 & 27.860 & 34.194 \\
\hline
\end{tabular}

Table 6. Experimental Mode Shapes

\begin{tabular}{|c|c|c|c|c|c|}
\hline $\begin{array}{c}\text { Mode } \\
\text { No. }\end{array}$ & 1 & 2 & 3 & 4 & 5 \\
\hline $\begin{array}{c}\text { Mode } \\
\text { shape }\end{array}$ & $\cdots$ & $\cdots$ & $\cdots$ & $\cdots$
\end{tabular}

\section{Natural Frequencies' Updating}

If we compare the initial theoretical and experimental natural frequency (Table 7), all the error of percentage was significant in every mode. If we investigate the degree of correlation between two sets of data, a plot of theoretical parameters versus measured ones in each mode separately was shown in Figure 5. 
Table 7. Difference Comparison between Theory and Measurement

\begin{tabular}{|c|c|c|c|}
\hline Mode No. & Measured f. [Hz] & Prediction [Hz] & Error [\%] \\
\hline 1 & 3.678 & 6.4953 & 43.37444 \\
\hline 2 & 9.589 & 14.395 & 33.38659 \\
\hline 3 & 21.067 & 37.820 & 44.29667 \\
\hline 4 & 27.860 & 41.869 & 33.45912 \\
\hline 5 & 34.194 & 53.054 & 35.54869 \\
\hline
\end{tabular}



Figure 5. Initial Prediction vs. Measurement

As seen from the figure, it is straightforward to find the correlation is so slow $(\mathrm{k}=$ $0.64)$ that the deviation from best fit $(\mathrm{k}=1)$ is large $(\delta=35.97 \%)$. In order to eliminate the difference to approach the target, the updating process was initialized. Several aspects of the updating factors should be investigated for the validation process.

\subsection{Material Properties ( $1^{\text {st }}$ Updating)}

It has been said that FEA overestimates stiffness [12-14]. This error will cause an overestimation of natural frequency as $\mathrm{f}=\sqrt{\mathrm{k} / \mathrm{m}}$. However, the material inputs for FEA in ANSYS are Young's modulus and density with a relationship to frequency: $\mathrm{f} \propto \sqrt{E / \rho}$. Hence, a slight decrease of $E$ or increase of $\rho$ would reduce the overestimation. Both variations were performed within the appropriate boundaries scale ( E: $10.5 \rightarrow$ $10 \mathrm{GPa} ; \rho: 2130 \rightarrow 2270 \mathrm{~kg} / \mathrm{m} 3$ ). The results were indicated in the following figure and table for the improvement after $1^{\text {st }}$ update.

Table 8. New Error after $1^{\text {st }}$ Update

\begin{tabular}{|c|c|c|c|}
\hline Mode Number & Measured $(\mathrm{Hz})$ & Predicted $(\mathrm{Hz})$ & Error $(\%)$ \\
\hline 1 & 3.678 & 6.1401 & 40.0987 \\
\hline 2 & 9.589 & 13.608 & 29.5341 \\
\hline 3 & 21.067 & 35.752 & 41.0746 \\
\hline 4 & 27.86 & 39.580 & 29.6109 \\
\hline 5 & 34.194 & 50.153 & 31.8206 \\
\hline
\end{tabular}




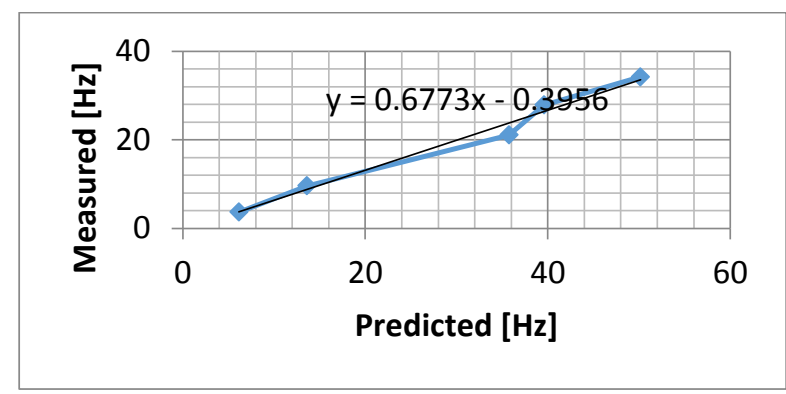

Figure 6. Improved Correlation after $1^{\text {st }}$ Update

The results indicated a slight improvement of correlation and a reduction both in error and deviation. The slope has also been improved from 0.640 to 0.677 ; an upgrading of 0.037 towards the target (best correlation), only 0.323 (32.3\%) away from unity.

\subsection{Pier-like Substructure ( $2^{\text {nd }}$ Update $)$}

In the preliminary prediction, the initial FE model simplified the real case of the free stand wall as a full rectangular plate defined a uniform thickness of $0.22 \mathrm{~m}$. However, in this updating procedure, the details of it should be discussed. As seen from the physical observation of the wall (Figure 7), it was found that the right column of the wall is a pierlike sub-structure (masonry column) acting like a stiffening member which has a different thickness of $0.33 \mathrm{~m}$.



\section{Figure 7. Front and Side View of Right Column of Wall}

If presented in ANSYS, this particular member should be considered separately as an independent element of defined thickness value during modelling process. Thus, different results of FE modelling would be obtained after this alteration:

Table 9. Comparison of $2^{\text {nd }}$ Updating Results

\begin{tabular}{|c|c|c|c|}
\hline Mode No. & Measurement [Hz] & Prediction [Hz] & Error [\%] \\
\hline 1 & 3.678 & 6.5043 & 43.4528 \\
\hline 2 & 9.589 & 13.095 & 26.7736 \\
\hline 3 & 21.067 & 32.108 & 34.3871 \\
\hline 4 & 27.86 & 39.609 & 29.6625 \\
\hline 5 & 34.194 & 51.204 & 33.2201 \\
\hline
\end{tabular}




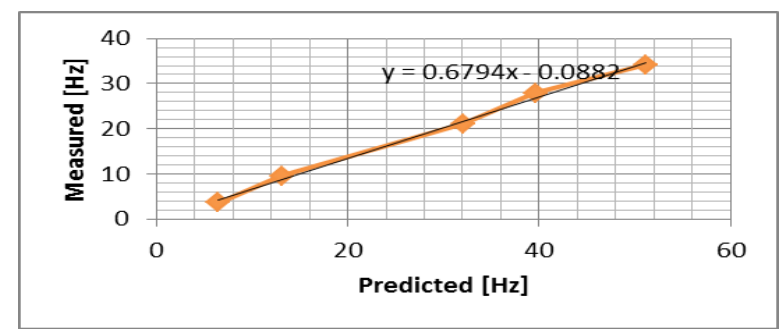

Figure 8. Correlation Slope of $2^{\text {nd }}$ Updating Data

It looks more complex of this update when comparing with the previous ones, especially the errors became larger in several modes and the others go by contraries. Hence, it is now not so easy to judge whether an improvement succeeds or not. It is the right moment to use the correlation relationship to check the controversy. If check the correlation slope (Figure 7), the deviation of 3nd mode had been eliminated significantly to make the trend line of slope became smoother. However, this change did not dominate the overall performance of improvement, this will be affected by a slightly poor improvement of correlation by $0.0021(<1 \%)$ which increase from 0.6773 to 0.6794 towards the target. To summarize the discussion, one could be concluded that this specific pier-like substructure would not play an important role to alter the value of modal parameters and structural behavior.

\subsection{Elastically Supported Built-in End ( $3^{\text {rd }}$ Update)}

If review the initial FE model, it was found that two boundary conditions (BCs) had been applied: the fixed edge in the bottom side and pinned supported connection at the left side end. However, practical experiences told us neither fully fixed nor pinned constrain occurs in real structure interfaces. Only in few cases, an approximation of fixed or pinned $\mathrm{BC}$ may be close enough to reality representation. Otherwise, the $\mathrm{BC}$ should be estimated approximately by a semi-fix (or semi-flexible) condition realistically. [2] considers a typical example of this particular elastic BC (Figure 2 as an example of this paper). The author did a simplification of this situation to an elastically supported or elastically built-in edge with an assumption to a rectangular plate which is considered to be coupled to a supporting beam elastically (Figure 9), this assumption will make the displacement of the interface be equal to the deflection of the beam.

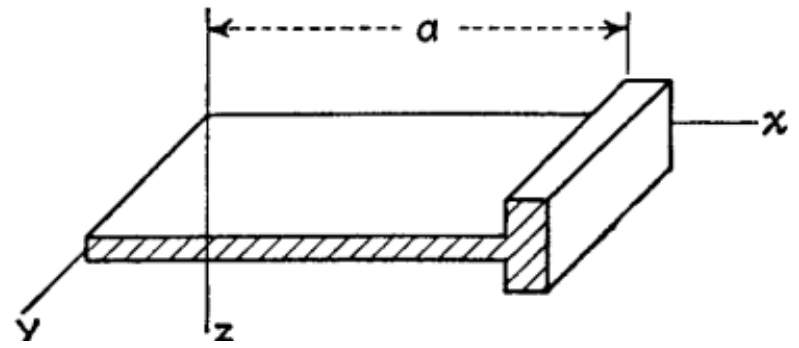

Figure 9. Example of Elastic Supporting Described in [2]

This BC prefers to employ several beam elements (BEAM188) with one fixed point of each element to perform this particular elastic property in ANSYS. BEAM188 is a linear 2-node beam element in 2-D FEM. However, in order to perform complex linear beam stiffness capability conditions, the arbitrary element MATRIX27 whose unique aptitude to allow the user full control of input parameters is a better option. Its structural dynamic response can be described by stiffness in matrix form. The matrices of this element are $12 \times 12$. If one node is fixed without movement, let all rows and columns of this node default to zero. The stiffness matrix constants are input as real constants. These constants 
could be calculated from the well-known established slope/deflection equations for a beam of flexural rigidity EI, the element stiffness matrix of Euler-Bernounlli Beam with length $l_{e}$ can be shown as follows:

$$
k_{e}=E I\left[\begin{array}{cccc}
\frac{12}{l_{e}^{3}} & \frac{6}{l_{e}^{2}} & -\frac{12}{l_{e}^{3}} & \frac{6}{l_{e}^{2}} \\
& \frac{4}{l_{e}} & -\frac{6}{l_{e}^{2}} & \frac{2}{l_{e}} \\
& \frac{12}{l_{e}^{3}} & -\frac{6}{l_{e}^{2}} \\
& & & \frac{4}{l_{e}}
\end{array}\right](1)
$$

The Young's modulus E in Equation 1 is uncertain and expected to be estimated from a relative high value (e.g. value of concrete) to a gradually decreased one towards the target. According to the literature survey of previous Lab. Tests conducted by [15], the measured concrete Modulus of Elasticity was $30.00 \mathrm{GPa}$. Meanwhile, the second moment of inertia I and length $l_{e}$ were calculated from the geometric size of length and cross section of supporting beam (clay strip at the connection interface), the support stiffness were finally derived from the above information (here taken $\mathrm{E}=14 \mathrm{GPa}$ as an example):

$$
k_{e}=\left[\begin{array}{cccc}
6.02 & 4.2 & -6.02 & 4.2 \\
4.2 & 3.99 & -4.2 & 2 \\
-6.02 & -4.2 & 6.02 & -4.2 \\
4.2 & 2 & -4.2 & 3.99
\end{array}\right] \times 10^{5}(2)
$$

This equation would be developed in ANSYS for DOFs:

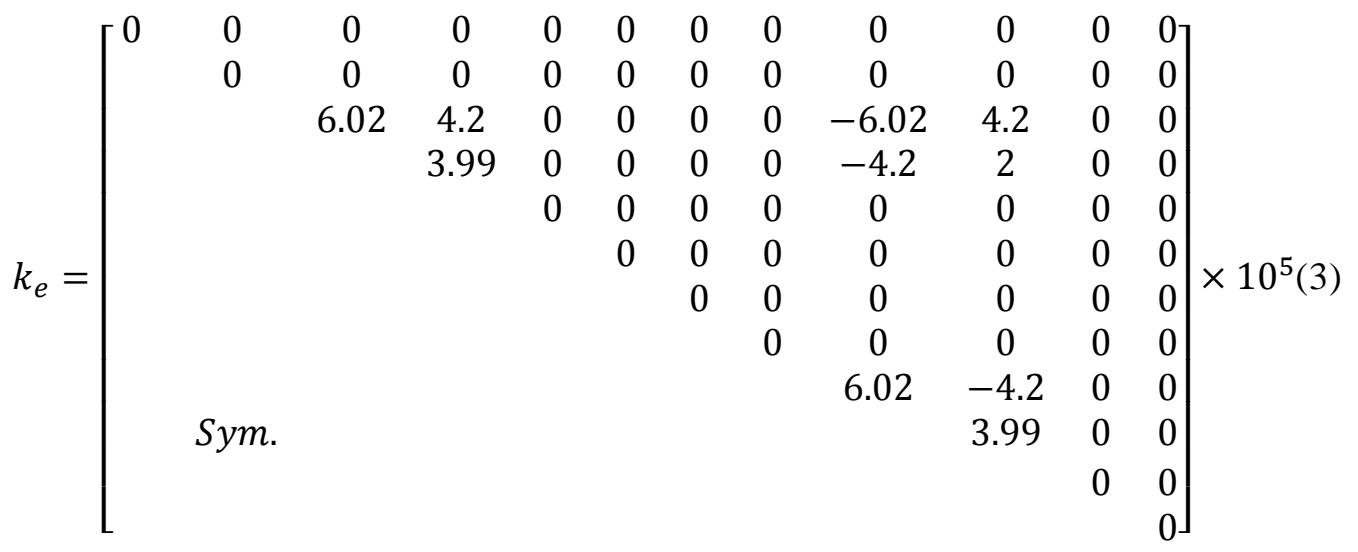

The results of natural frequencies predicted by FEA were located in Table 10 and Figure 10 comparing with measurement $(\mathrm{E}=14 \mathrm{GPa})$.

Table 10. Prediction and Measurement Comparison (Modal Frequencies)

\begin{tabular}{|c|c|c|c|}
\hline Mode No. & Measured f. [Hz] & Predicted f. [Hz] & \% Error \\
\hline 1 & 3.678 & 6.4637 & 43.0976 \\
\hline 2 & 9.589 & 12.938 & 25.885 \\
\hline 3 & 21.067 & 31.452 & 33.0186 \\
\hline 4 & 27.86 & 39.242 & 29.0046 \\
\hline 5 & 34.194 & 50.082 & 31.724 \\
\hline
\end{tabular}




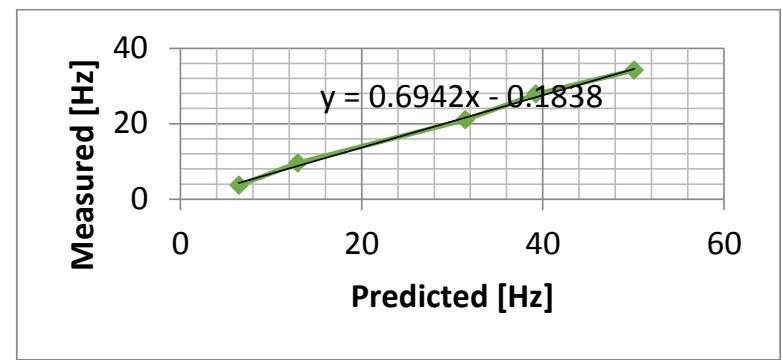

Figure 10. Correlation for MATRIX27 with E=14GPa

If gradually increase Young's modulus (E) from zero (free BC) to more than $40 \mathrm{GPa}$ (towards rigid/fixed $\mathrm{BC}$ ), it was found that the improvement of correlation slope became very slow once $\mathrm{E}$ beyond a saturation point where $\mathrm{E}=14 \mathrm{GPa}$ (Figure 11) and the best correlation could be confirmed near the saturation point with the value of 0.6942 .



Figure 11. The Trend Curve of E with a Saturation Point at $E=14 \mathrm{GPa}$

The conclusion could be made that a more accurate boundary condition affects the correlation result significantly. The slope of the trend line has changed from 0.6794 to 0.6942 , a better fit towards target of 0.0148 and 0.3058 (30.58\%) away from perfect correlation.

\subsection{Fine Tuning}

This tuning was developed on the result of $1^{\text {st }}$ update regarding masonry's material properties and was tuned carefully to achieve small adjustment towards perfect correlation. Thus, Young's modulus of masonry decreased slightly to $9.75 \mathrm{GPa}$ and its density increased to $2320 \mathrm{~kg} / \mathrm{m} 3$. It is accepted that the former is inside the range of valued given in previous test and also the European Standard. The density still lies in the scale of the bounds given by British Standard. The results from the tuning are shown in Table 11 and Figure 12.

Table 11. Comparison of Frequencies after FE Fine-tuning

\begin{tabular}{|c|c|c|c|}
\hline Modal No. & Measured f. [Hz] & Predicted f. [Hz] & \% Error \\
\hline 1 & 3.678 & 6.4557 & 43.0271 \\
\hline 2 & 9.589 & 12.927 & 25.8219 \\
\hline 3 & 21.067 & 30.95 & 31.9321 \\
\hline 4 & 27.86 & 38.458 & 27.5573 \\
\hline 5 & 34.194 & 49.095 & 30.3514 \\
\hline
\end{tabular}




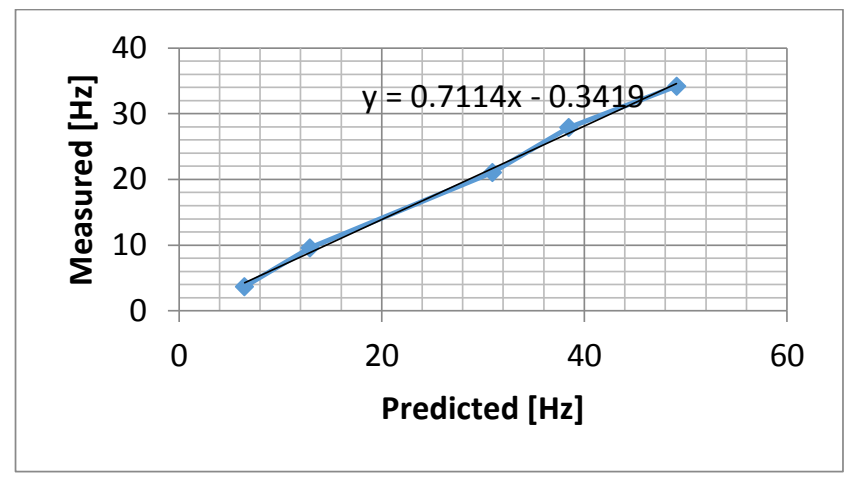

Figure 12. Final Correlation

The fine tuning procedure changed the slope of the trend line from a former value 0.6942 to an improved one 0.7114 . This is a fine adjustment of only 0.0172 towards target but it could be verified and justified easily during the FEM updating process. At last, the final validation value would be $0.2886(28.86 \%)$ away from perfect correlation and could be further updated in another FEA later.

\section{Commentary on the Results}

The major arguments in terms of the results had been discussed in the previous section but two supplementary comments need also be clarified. It should be stressed that the correlation relationship depends on many variables but their degree of sensitivity varies. Correlation is particularly sensitive to the material properties of brickwork and boundary edges of the masonry structure. Figure 13a indicated how far the actual correlation deviated from the target value of best fit regarding each updating procedure. The results of $3.7 \%$ between the preliminary model and the one after $1^{\text {st }}$ update and that of $1.48 \%$ between the $2^{\text {nd }}$ and $3^{\text {rd }}$ updates, explain why the material properties and boundary conditions are the most important variables which need pay attention to during the whole updating process. Similarly Figure 13b showed each improvement in an effort towards best fit of unity.

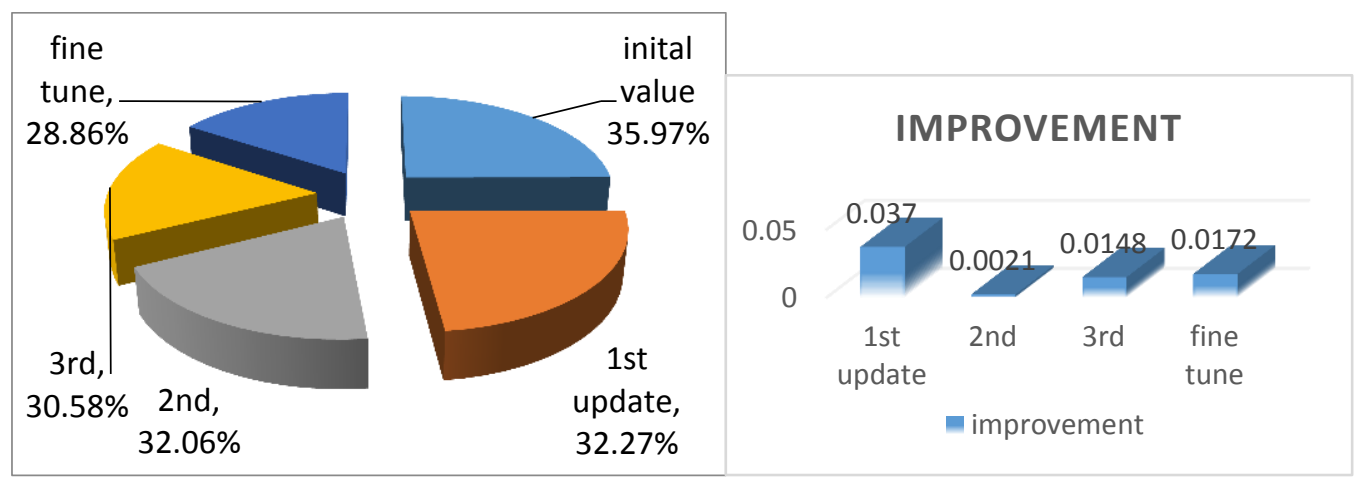

Figure 13(a). Percentage of Slope 


\section{Harmonic Analysis}

After validating natural frequencies of theoretical modal analysis, the modal parameters looks robust now for the purpose of vibration prediction. It had been demonstrated that Harmonic Analysis in FEA is an effective way to predict the structural behavior using the results obtained from modal analysis with known input force. This analysis would determine the structural response under a steady-state sinusoidal (harmonic) loading at a given frequency. This is in accordance with the working principle of wind turbine with a rotational speed (RPM)/frequency. In a harmonic analysis, the loading/force and response/vibration level of the structure is assumed to be harmonic (cyclic):

$$
\begin{array}{r}
f(t)=F(\omega) \sin \omega t \\
x(t)=X(\omega) \sin \omega \text { twhere } \omega=2 \pi f ; f=\frac{R P M}{60}(4)
\end{array}
$$

\subsection{Force Identification (A New Indirect/Inverse Force Estimation Method)}

The explanation from above paragraph told us that in order to perform a harmonic analysis, the excitation contact force or loading at the interface between wall and turbine must be determined or measured. It is straightforward to quantify this force using a direct measurement by a force transducer inserted into the interface. If we assume the interface constituting of a set of single points, the inserting of a transducer with good calibration at the interface points possibly measure the force exerted on the interface directly. The simplified case for one DOF is known in [17] and the approach is sensible to work. However, there is technical difficulty in practical.

Figure 14 is a good schematic illustration of the coupling points of an assembly for a representative wind turbine (source) and mounting system (receiver). Seen from the figure it is clear to see that the bearing of wind turbine and its mounting peripheral are connected by inserting the stub into the suitable hole of mounting pole.
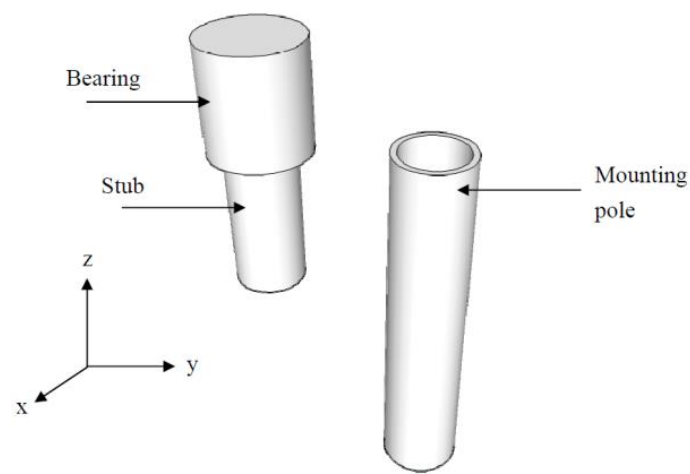

Figure 13. Bearing, Stub, Mounting Pole for Coupling

However, during the practical mounting process, it was impossible or difficult to integrate even very small force sensors (with cables) into the coupling points between source and receiver unless modifying the source and/or receiver structure. Furthermore, it is not easy to design the way how forces in the vertical direction which perpendicular to the wall plane could be measured at all, without the consideration of possible moment measurements about the $\mathrm{x}$ and $\mathrm{y}$ axes even. Modification of the source and receiver structure had been investigated and tested however this would reduce confidence level of the measurement of force dramatically. Thus not a good option for this case. 
For the instances which direct measurements are not available, the author had developed a novel alternative approach - indirect/inverse force determination which determines the force inversely from more easily obtained quantities: the vibration levels of structural response; mathematical relationships between excitation and response. This new method was proposed from the ideas of experiment and developed by theory of structural dynamics. Above all, the force is easily to be written in the form of mass and acceleration which derived from Newton's Second Law:

$F(\omega)=m A(\omega)(5)$

Where $\mathrm{A}$ is the amplitude of the acceleration expression in sinusoidal format regarding periodic forced vibration: $\mathrm{a}(\mathrm{t})=\mathrm{A}(\omega) \sin (\omega \mathrm{t}+\Phi)$. This is a 1DOF simple case since the test object had been treated as a rigid body without considering stiffness and damping. In multiple DOFs case, the mass of object will be replaced by accelerance in matrix form in vibration theory. The acceleration levels could be measured and recorded by an accelerometer during the experiment.

In general, structural dynamics would include the effects of stiffness, damping, mass and excitation frequency $(\omega)$. Hence, the initial ideas stated above could be developed by a steady state solution of dynamic response in 1DOF:

$X(\omega)=H(\omega) \cdot F(\omega)(6)$

$\mathrm{H}(\omega)$ is called frequency response function or transfer function. It is the ratio of displacement/force spectral and defined as a function of frequency $(\omega)$ :

$$
\begin{aligned}
& H(\omega)=\frac{R}{j \omega-p}+\frac{R^{*}}{j \omega-p^{*}} \\
& R=-j \frac{1}{2 m \omega_{d}} R^{*}=j \frac{1}{2 m \omega_{d}} \\
& p=-\sigma+j \omega_{d} p^{*}=-\sigma-j \omega_{d} \\
& \omega_{0}^{2}=\omega_{d}^{2}+\sigma^{2}(7)
\end{aligned}
$$

In these equations, $H(\omega)$ is defined in terms of two variables: $p$ (pole location) and $R$ (the residue); $p^{*}$ and $R^{*}$ denote their complex conjugates. The real part of $\mathrm{p}$ is the rate at which a vibration decays due to damping $(\sigma)$. Its value is determined by half the $-3 \mathrm{~dB}$ bandwidth of the frequency response function (FRF) peak. The imaginary part is the damped natural frequency $\left(\omega_{d}\right)$ for a free damped vibration. Both $\mathrm{p}$ and $\mathrm{R}$ can be obtained from measurements of FRF. The FRF could be measured from an experimental modal analysis or structural testing indicated in the previous section. The deflection $X(\omega)$ is the amplitude of displacement and according to the physics, displacement is the double integral of acceleration.

If more accurate results were required, FEA is needed to subdivide the whole structure into several parts (finite element) [18]. Previous models falls into a category of single DOF (SDOF) with one movement direction. However, complex structures usually have a series of points and different directions upon each point - multiple DOFs in total. Thus

$$
\begin{aligned}
& H_{i j}(\omega)=\frac{X_{i}(\omega)}{F_{j}(\omega)} \\
& H_{i j}(\omega)=\sum_{r=1}^{m} H_{i j_{r}}(\omega)(8)
\end{aligned}
$$

Index $\mathrm{i}$ - any response DOF, $\mathrm{j}$ - arbitrary excitation DOF, $\mathrm{r}$ - any normal mode, $\mathrm{m}-$ number of modes used in this model. The whole mathematical calculation could be performed in MATLAB or other vibration professional software (such as LMS LAB test 12B) and one representative data of the final results was indicated in the following figure: 


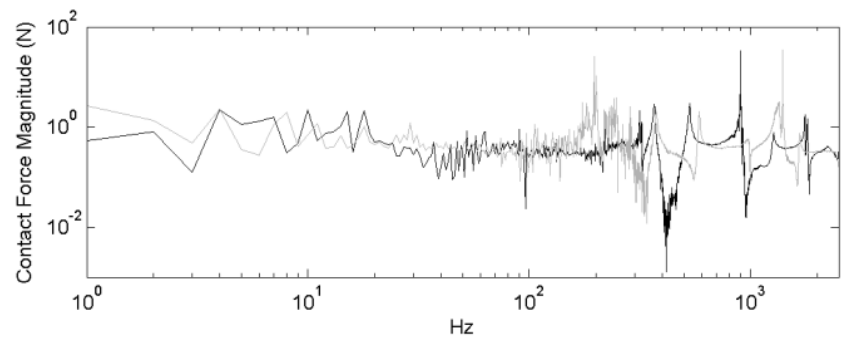

Figure 14. Force Estimation by Inverse Method for Two Contact Points

Once the force was determined, the harmonic analysis would be conducted using ANSYS 12.0. The frequency of the load would be varied from $1-50 \mathrm{~Hz}$ (due to a maximal safety speed of 3000rpm permitted for wind turbine). Stepped boundary condition (KBC) was chosen for the initial trial to ensure that the same amplitude $(10 \mathrm{~N})$ would be applied for each of the frequencies. The initial results from harmonic analysis were shown below:

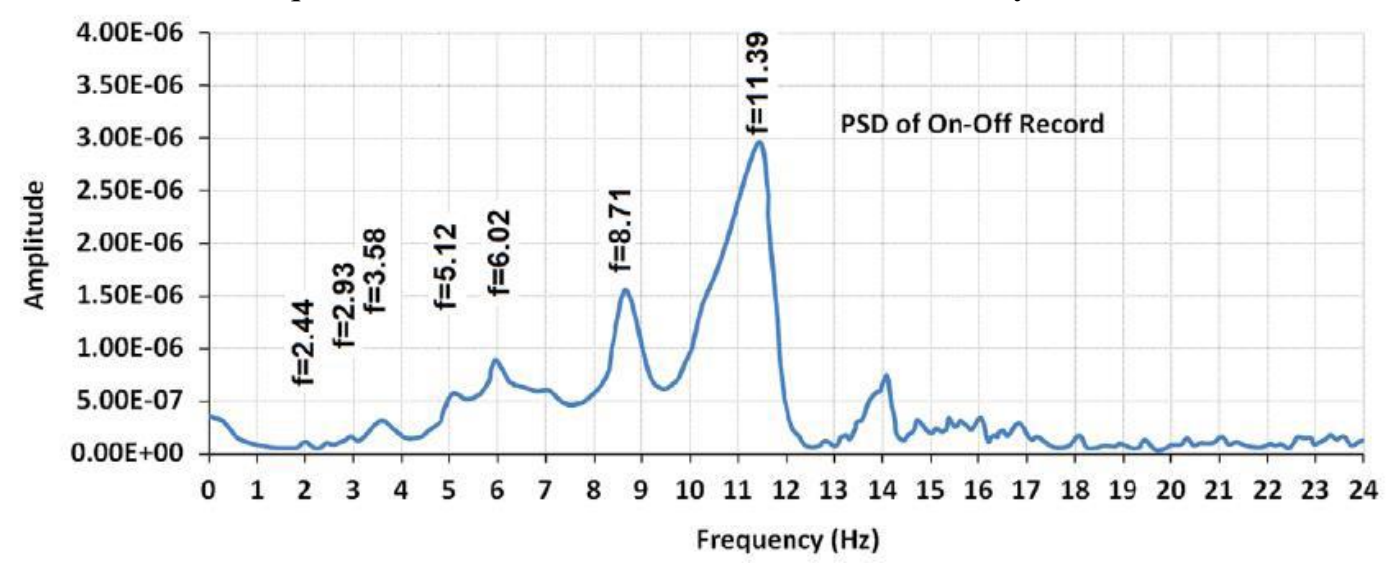

\section{Figure 15. Initial Vibration Level Prediction within Selected Frequency Range}

\section{Vibration Level Measurement - A Novel Lab Simulation Method}

Although the predicted vibration level had been obtained, it was not robust and need also be verified or validated by a $2^{\text {nd }}$ updating. Before the updating process, the actual experimental vibration level should be measured by Lab Testing. The test rig requires the mounting of a small wind turbine upon the surface of the wall (Figure 1). However, there is a technical problem since no wind power could be supplied inside the Lab to drive the turbine to work normally. An artificial wind power (e.g. large electric fan) is impossible from the practical point of view of safety since this will inevitably blow off everything in the Lab! (A minimal wind speed required for wind turbine working is at least $5 \mathrm{~m} / \mathrm{s}$ ) Consequently, the author proposed a new approach to modify the internal configuration of the turbine and replace the generator inside turbine housing with a DC motor using electronic supply. The main section of simulation process is reproduction of rotational speed (RPM), in other words, it is necessary to control the motor's velocity automatically to the desired or expected value. PID controller is the core of speed control andthe abbreviation of proportional-integral-derivative which is a generic control loop feedback mechanism widespread in control engineering. This particular controller calculates the error between a measured process variable and a desired set point and attempts to eliminate the difference via modifying the process inputs [26]. In Figure 16 a schematic diagram of a PID system. 


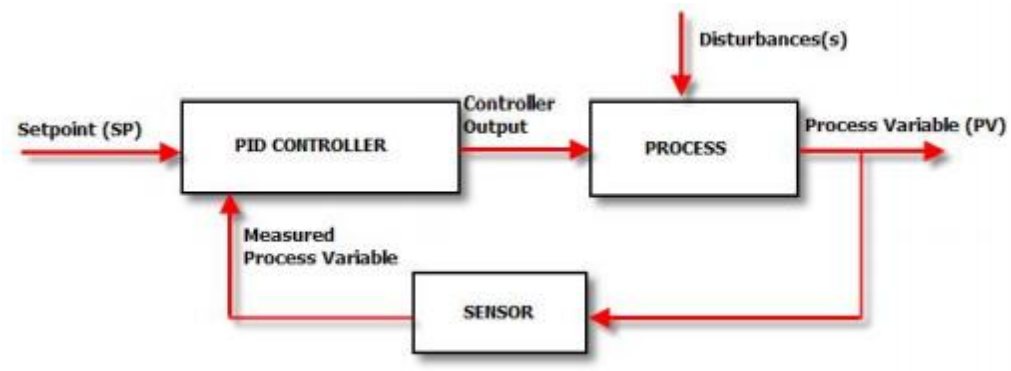

Figure 16. PID-Controlled Closed Loop System

The whole control and feedback process including PID controller could be modelled and designed by a computer program used in LABVIEW (Figure 17). The required hardware for this closed-loop control system were introduced in the consequent paragraph.

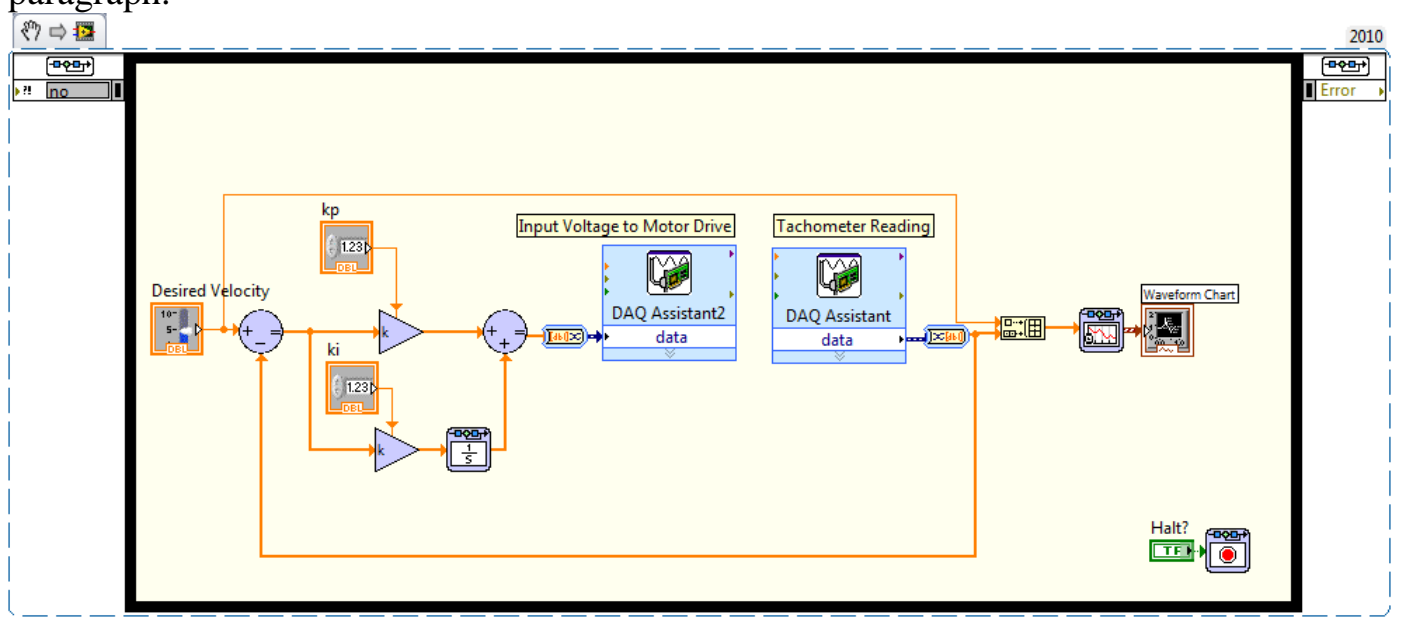

Figure 17. Solution Block Diagram VI Snippet

The National Instrument (NI) PCI-6221 card is a data acquisition (DAQ) board which capture the digital signal of PID controller in the computer and also a digital-to-analog converter (DAC) which is a function that converts digital data (usually binary) into an analog signal (current, voltage or electric charge). The SC-2075 connects the analog inputs/outputs (I/O) including BNC and breadboard connectors compatible with PCI 6221 DAQ devices which is a connector accessory for constructing circuits and connecting them conveniently to virtual instruments (e.g. PID controller). A Built-in $\pm 15 \mathrm{~V}$ or adjustable $0-5 \mathrm{~V}$ power supply is available to build op-amp circuits. It features two binding posts for analog inputs and 3 for $15 \mathrm{~V}$ outputs or 2 for $0-5 \mathrm{~V}$ outputs. The Copley Control 300 Series amplifiers is typically used as a voltage-to-current converter. $\pm 10 \mathrm{~V}$ reference signals from SC-2075 will drive the amplifier's peak rated current to the load in the 'flat-gain' mode.All units feature fully differential inputs for the control, or reference voltage. Enable inputs for output control, a status output, and a current monitor signal ease system interfacing. To install the amplifier you will need a control or reference voltage, a power supply and a load. The power supply was ordered from Copley Control (662) and operates from 16 to 160 volt single-output DC power.The series 600 power supplies have been designed to compliment Copley Controls servo amplifiers and to provide the user with a complete solution to single and multi axis DC drive applications. Amplifier connections were shown in figure 18 and numbered terminals are on the brown 22-pin connector. Double-letter terminals are on the orange 4-pin connector. 


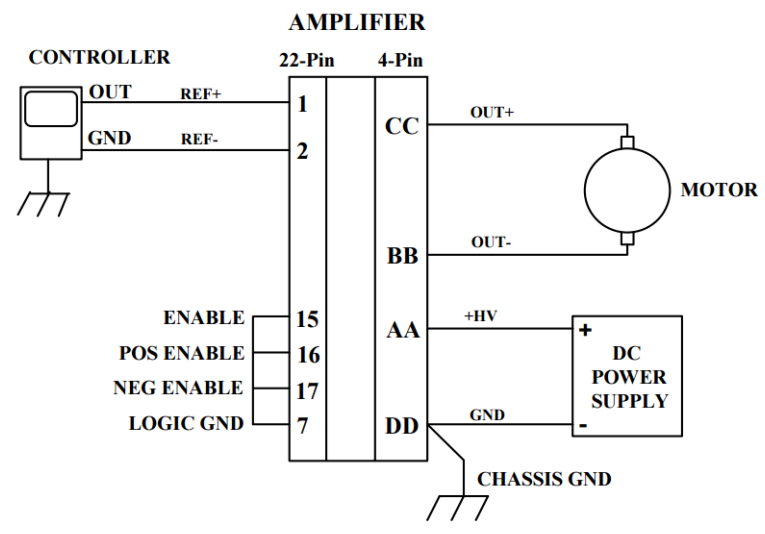

Figure 18. Basic Amplifier: Current-Mode, NO Tachometer

The loading system include microprocessor control systems that get velocity feedback from an encoder on the servo motor that require a set current from the amplifier in response to a control-voltage at the inputs. A servo motor is a rotary actuator or linear actuator that allows for precise control of angular or linear position, velocity and acceleration. It is often used to refer to a motor suitable for use in a closed-loop control system.

A rotary encoder, also called a shaft encoder, is an electro-mechanical device that converts the angular position or motion of a shaft or axle to an analog or digital code. An incremental rotary encoder provides cyclical outputs (only) when the encoder is rotated. It is the most widely used of all rotary encoders due to its low cost and ability to provide signals that can be easily interpreted to provide motion related information such as velocity. Incremental encoders employ two outputs called A \& B, which are called quadrature outputs, as they are 90 degrees out of phase.



Figure 19. Two Square Waves in Quadrature (Clockwise Rotation)

The two output wave forms are 90 degrees out of phase, which is what quadrature means. These signals are decoded to produce a count up pulse or a count down pulse. For decoding in software, the A \& B outputs are read by software, either via an interrupt on any edge or polling.

An observer, such as a microprocessor (PCI-6221 board), will read (sample) the output of the encoder with the function of edge counting. The pulse per revolution (PPR) of the encoder is 600 . The Lab test rig for the control process would be shown as a flow chart. 


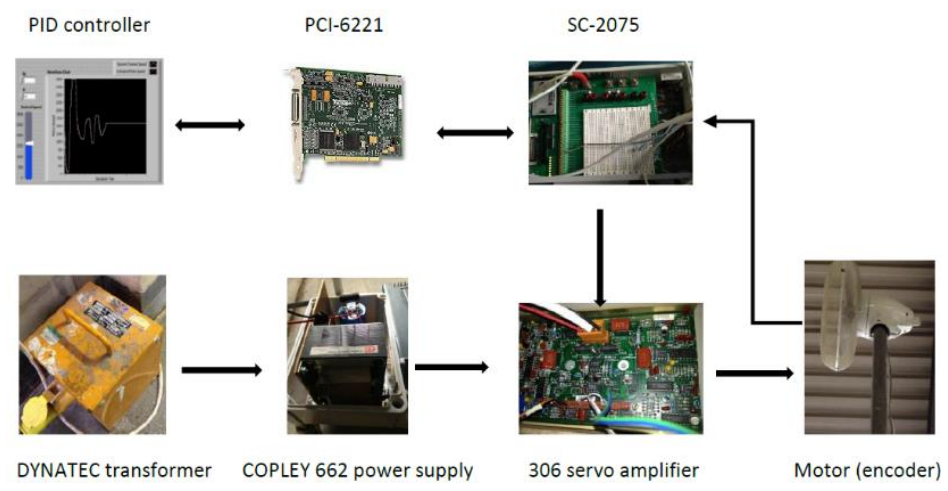

\section{Figure 20. Speed Control Diagram of 600W DC Motor with PID Controller}

As seen from the figure, a 600W DC servo motor was designed by a PID controller in Control Design and Simulation Module in LABVIEW. The measured process variable of motor for experiment would be adjusted to approach the actual response of wind turbine in the field through modifying the desired set-point (input). This simulation process requires the desired velocity from field test and these data were generated and collected by author when collaborating with our industrial partner - AMPAIR wind turbine ltd. During the data collection measurement, more than 10000 samples were obtained by a long-term observation (Figure 21), the RPM is pulses averaged mean over 10s period. Furthermore, a 10min time history (scenario) of rotational speed was plotted according to the samples (Figure 22).



Figure 21. A600 Rotor Speed vs. Wind Speed (10s Avg. Data)

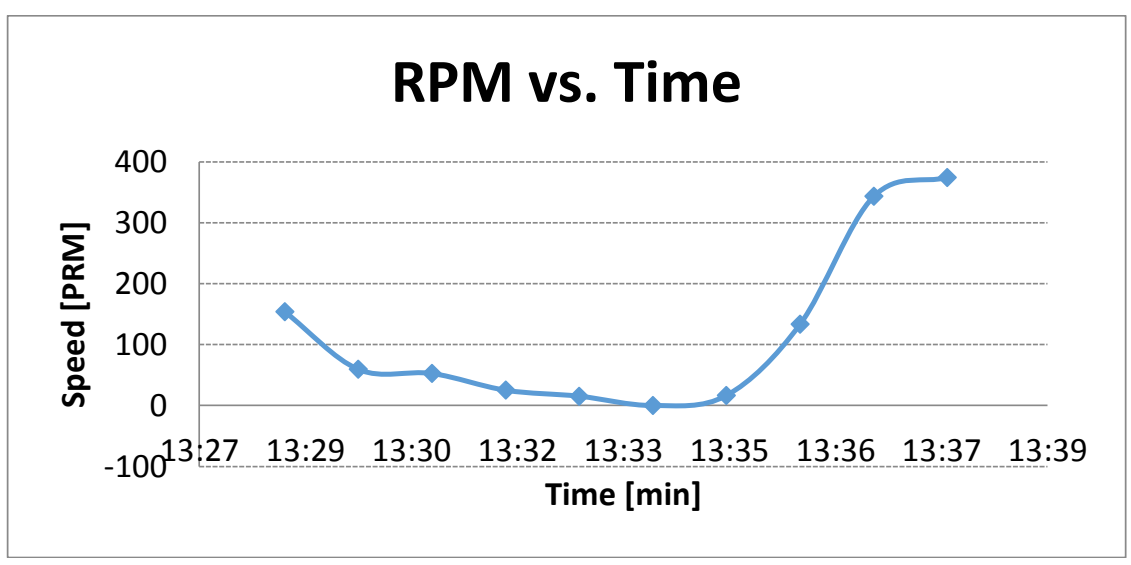

Figure 22. Plot of RPM Time History Map 
Once the speed profile was input into LABVIW one by one like real-time data in the form of Excel format or XL, the loop of the simulation control process would be completed and the motor would work as the same of turbine in the outside field. Therefore, the corresponding amount of vibration could be measured by LMS pimento shortly afterwards.



Figure 23. Measured Vibration Level in Frequency Domain

\section{Vibration Response Updating (Resonant Frequency)}

Once both theoretical and experimental harmonic response (Figure $15 \& 23$ ) had been obtained, the most important modal parameter - resonant frequency of forced vibration behavior could be also validated during another updating process. Above all, the initial relationship and comparison of the two sets of data had been plotted in Figure 24.



Figure 24. Initial Correlation between Predicted Resonant Freq. and Measured Ones

\subsection{Frequency Range Set ( $1^{\text {st }}$ Update)}

The initial FEM for harmonic analysis specified a stepped boundary condition (KBC) to ensure the same amplitude $(10 \mathrm{~N})$ would be applied for each of the frequency sub-steps. However, it is not correct for the force calculation of wind turbine which is determined by and depend on the corresponding RPM or frequency. Hence, more accurate model with ramped option seems better which ramps up the amplitude where $1 \mathrm{~N}$ at $1 \mathrm{~Hz}$ and $10 \mathrm{~N}$ at $10 \mathrm{~Hz}$. After this update, the improved results were collected in the following tables and figure. 
Table 12. FE and Experimental Model after $1^{\text {st }}$ Updating

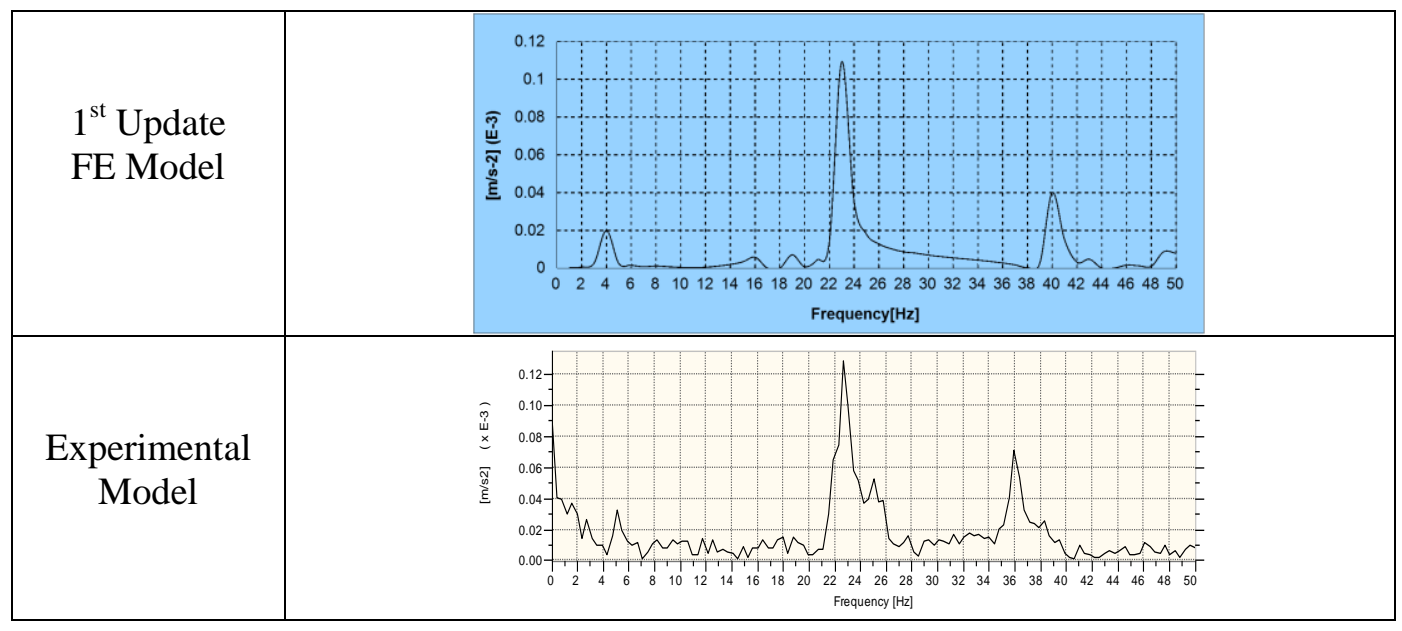

Table 13. Resonant Frequencies Comparison

\begin{tabular}{ccccc}
\hline Mode & Predicted & Measured & Error (\%) & SD \\
No. & $f .(\mathrm{Hz})$ & $f .(\mathrm{Hz})$ & & $(\%)$ \\
1 & 4.012 & 5.179 & 22.500 & 5.39 \\
2 & 23.133 & 22.800 & 1.461 & 1.01 \\
3 & 40.009 & 35.891 & 11.473 & 3.00 \\
\hline
\end{tabular}



Figure 25. First Correlation between Two Sets Data

The slope of correlation has changed from 0.814 to 0.855 , an improvement of 0.041 and only $0.145(14.5 \%)$ deviated from unity of best fit.

\subsection{Solution Techniques ( $2^{\text {nd }}$ Update)}

ANSYS could solve the harmonic analysis by different solution methods and one of them - subspace method was adopted initially for primary solving purpose. It uses the generalized Jacobi Iteration Algorithm [19] which is similar with the Gauss-Seidel iteration. However, most of the researchers of structural dynamics recommended the Block Lanczos eigenvalue extraction method [20] for complete and accurate solution. This approach uses block matrices to represent Lanczos algorithm using the sparse matrix solver [21]. The relevant modifications of the results by different solver were obtained below: 
Table 14. FE and Experimental Model after 2nd Updating

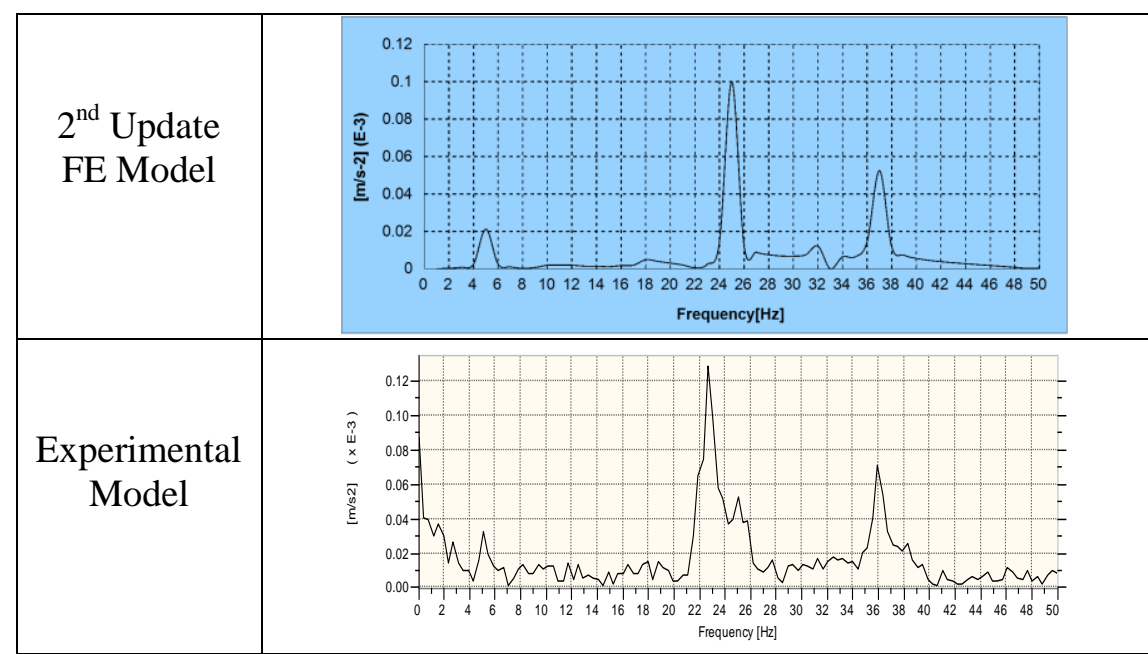

Table 15. $2^{\text {nd }}$ FE Update (Resonant Frequencies Comparison)

\begin{tabular}{ccccc}
\hline Mode & Predicted & Measured & Error (\%) & SD \\
No. & $f .(\mathrm{Hz})$ & $f .(\mathrm{Hz})$ & & $(\%)$ \\
1 & 4.812 & 5.179 & 7.086 & 2.56 \\
2 & 24.723 & 22.800 & 8.447 & 4.72 \\
3 & 36.811 & 35.891 & 2.563 & 0.94 \\
\hline
\end{tabular}

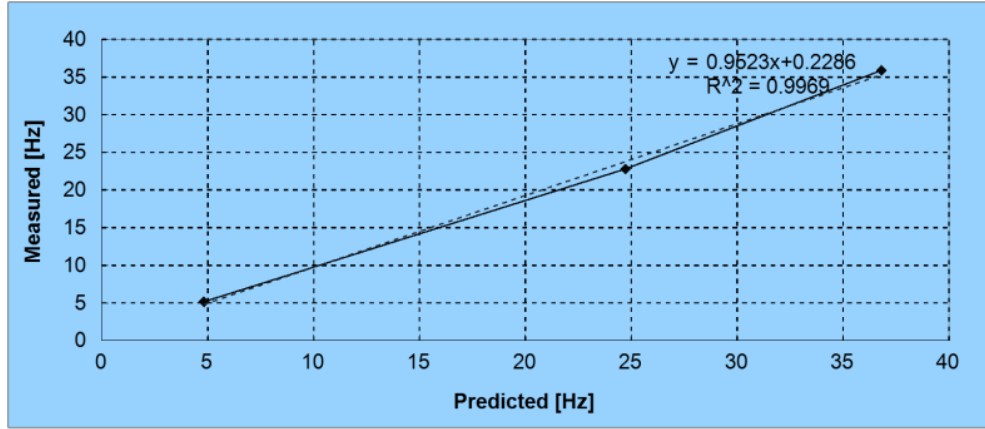

Figure 26. Correlation of the $2^{\text {nd }}$ Updating Results

As seen from the figure the prediction converges gradually towards the measurements and the rate of the standard deviation is also decreasing. Moreover, the error between last and present slope decreases ( 0.8547 to 0.9523 ), a significant improvement of up to 0.0976 $(9.76 \%)$ and 'road' to the target is now only 0.0477 or $4.77 \%$.

\subsection{Summary}

The methodology to predict the impacts (FEA) should be sufficiently robust now that decisions relating to the amenity (not merely) of neighboring properties can be predicted. This is achieved by testing a hypothesis through laboratory/field tests on a statistically valid sample size (statistically analysis) and through a series of rigorous finite element models (numerical analysis). By validating and verifying the above hypothesis using numerical and analytical (mathematical) models. 


\section{Concluding Comments}

- In order to achieve automatic control of motor speed, the real-time wind speed profile should be read one by one with a few milliseconds time delay by LABVIEW in a form of a particular file (text or XL). An index array function would be used to get the column required and be wired to a For Loop with a 'Wait Until Next ms Multiple' module inside of the loop.

- Timing is an important consideration when using the LabVIEW Control Design and Simulation Loop with real hardware. Since the Control Design and Simulation Loop uses a built in ODE solver with time steps, it is important to set the Simulation Parameters and the Timing Parameters of the loop to have the same time step. Data acquisition tasks typically use timing parameters, so it is also important to equate the Simulation loop timing with the data acquisition timing.

- With buffered edge counting (edge counting using a sample clock), the counter counts the number of edges on the Source input after the counter is armed. The value of the counter is sampled on each active edge of a sample clock. A DMA controller transfers the sampled values to host memory.

- The number of DOFs has to be chosen to represent the total dynamics of the structure. It is the geometrical complexity of the mode shapes, rather than to the number of modes expected, which determines the number of DOFs required.

- There is relatively good agreement between mode shapes from the experimental and the finite element modal analysis. Mode 1 is the fundamental bending mode of vibration. Mode 2 is of some interest as an almost predominantly torsional mode also showing small amounted of bending and Mode 3 similar to Mode 2. It would be very difficult to interpret it without the help of FEA. Note that plane symmetry has been applied to all FE-models and therefore only half the models are shown. It should be stressed again that without the help of the finite element analysis it would be difficult to interpret any complex modes based on the experimental results alone. Mode 2 and 3 represent twisting tendencies of the rectangular plane-shape thin plate unit (depicted successfully in the FE analysis) whereas Mode 4 and 5, may be regarded as the second and third 'bending-like' modes of vibration. Mode 5 also inhibits a small amount of torsion.

\section{Acknowledgments}

The financial support of the Engineering Faculty of Sheffield University and AMPAIR wind turbine ltd for all materials for testing (turbines, their peripherals, installation, knowhow, etc.) provided as in-kind support, is gratefully acknowledged. The collaborating company invested a nominal amount of cash in the project and team-up in an RAE studentship application, is much appreciated.

\section{References}

[1] Wilson, E. L., \&Habibullah, A., "SAP2000 - structural analysis users manual", Computers and Structures, Inc., (1998).

[2] Timoshenko, S. P., \&Woinowsky-Krieger, S., "Theory of plates and shells", McGraw-hill, (1959)

[3] Nichols, J. M., \&Totoev, Y. Z.,"Experimental determination of the dynamic Modulus of Elasticity of masonry units", 15th ACMSM.(1997).

[4] Pande, G. N., Liang, J. X., \& Middleton, J.,"Equivalent elastic moduli for brick masonry", Computers and Geotechnics, 8(3), (1989),pp. 243-265.

[5] Sassoni, E., Mazzotti, C., \&Pagliai, G., "Comparison between experimental methods for evaluating the compressive strength of existing masonry buildings", Construction and Building Materials, 68, (2014),pp. 206-219.

[6] Erdogmus, E., \& Boothby, T., "Strength of spandrel walls in masonry arch bridges", Transportation Research Record: Journal of the Transportation Research Board, (2004), pp. 47-55. 
[7] EN 1996-1-1 (English): Eurocode 6: Design of masonry structures - Part 1-1: General rules for reinforced and unreinforced masonry structures [Authority: The European Union Per Regulation 305/2011, Directive 98/34/EC, Directive 2004/18/EC](2005).

[8] EN 1996-3 (English): Eurocode 6: Design of masonry structures - Part 3: Simplified calculation methods for unreinforced masonry structures [Authority: The European Union Per Regulation 305/2011, Directive 98/34/EC, Directive 2004/18/EC](2006).

[9] EN 998-2, Specification for mortar for masonry - Part 2: Masonry mortar

[10] BS EN 771-1, Specification for masonry units. Clay masonry units, (2011).

[11] BS NA EN 1996-3 (English): UK National Annex to Eurocode 6. Design of masonry structures. Simplified calculation methods for unreinforced masonry structures, (2006).

[12] Hyo-GyoungKwak, Filippou, F.C., "Finite Element Analysis of Reinforced Concrete Structures under Monotonic Loads", Structural Engineering Mechanics and Materials, PhD Thesis, Dept of Civil Engineering University of California, Berkeley, California, Report No. UCB/SEMM-90/14,(1990).

[13] Ha-Wong Song, Sang-Hyo Shim, Keun-Joo Byun, and Koichi Maekawa, "Failure Analysis of Reinforced Concrete Shell Structures using Layered Shell Element with Pressure Node", Journal of Structural Engineering, 128 (5), (2002), pp. 655-664.

[14] Sherif, A.G. \&Dilger, W.H., "Analysis and deflections of reinforced concrete flat slabs", Canadian Journal of Civil Engineering, 25 (3), (2006), pp. 451-466.

[15] Karadelis, J.N., "Concrete Grandstands. Part I. Experimental Investigation", Proceedings of the Institution of Civil Engineers, Engineering and Computational Mechanics Journal 161, Issue EM1, doi: 101680/eacm.162.1.3, 3-9, (2009).

[16] Allemang, R. J., \& Brown, D. L., "A correlation coefficient for modal vector analysis", In Proceedings of the 1st international modal analysis conference (Vol. 1). SEM, Orlando, (1982) November, pp. 110-116.

[17] Lai, H.Y.,"Experimental Comparison of Test Methods for Structure-BorneSound Power Measurement", In SAE 2007 Noise and Vibration Conference andExhibitionSAE International, (2007).

[18] Reddy, J.N.,"An Introduction to the Finite Element Method (Third ed.)”, McGraw-Hill, ISBN 9780071267618, (2006).

[19] Mahinthakumar, G.A., Hoole, S.R.H.,"A Parallelized Element-by-Element JacobiConjugate Gradients Algorithm for Field Problems, and a Comparison with OtherSchemes", Applied Electromagnetics in Materials, 1, (1990), pp. 15-28.

[20] Lanczos, C., "An iterative method for the solution of the eigenvalue problem of linear differential operators", J Res. Natural Bureau of Standards, 45, (1950), pp. 255-282.

[21] Lewis, J.G., Grimes, R.G., Simon, H.D., "A Shifted Block Lanczos Algorithm for Solving Sparse Symmetric Generalized Eigenproblems", SIAM Journal of Matrix AnalysisApplications, Society for Industrial and Applied Mathematics, 15 (1), (1994), pp. 228-272.

[22] Hajihassani, M., Armaghani, D. J., Marto, A., \& Mohamad, E. T., "Ground vibration prediction in quarry blasting through an artificial neural network optimized by imperialist competitive algorithm", Bulletin of Engineering Geology and the Environment, 74(3), (2015), pp. 873-886.

[23] Hajihassani, M., Armaghani, D. J., Monjezi, M., Mohamad, E. T., \&Marto, A.,"Blast-induced air and ground vibration prediction: a particle swarm optimization-based artificial neural network approach", Environmental Earth Sciences, 74(4), (2015), pp. 2799-2817.

[24] Lombaert, G., Degrande, G., François, S., \& Thompson, D. J.,"Ground-borne vibration due to railway traffic: a review of excitation mechanisms, prediction methods and mitigation measures. In Noise and vibration mitigation for rail transportation systems", Springer Berlin Heidelberg, (2015), pp. 253-287.

[25] Ghoraba, S., Monjezi, M., Talebi, N., Moghadam, M. R., \&JahedArmaghani, D.,"Prediction of ground vibration caused by blasting operations through a neural network approach: a case study of Gol-E-Gohar Iron Mine.Iran.”, J Zhejiang UnivSci A. doi, 10, 1631, (2015).

[26] Detchratet. al., "IMC-Based PID Controllers Design for Two-Mass System", IMECS Volume - II, Hong Kong, (2012).

\section{Authors}



Bo Ren, received the B. Eng degree in Built Environmental and Equipment Engineering from Harbin Institute of Technology and $\mathrm{M}$. Eng. Degree in Structural Engineering from Sheffield University. He is currently researching on structural dynamics and vibration. 
International Journal of Signal Processing, Image Processing and Pattern Recognition Vol. 9, No. 5 (2016) 